\title{
Achieving Intervention Coherence in Routine Practice: A Qualitative Case-Based Study From An Implementer Perspective
}

Avril Nicoll ( $\sim$ avril.nicoll@abdn.ac.uk)

Aberdeen University https://orcid.org/0000-0001-9677-4817

Margaret Maxwell

University of Stirling

Brian Williams

Edinburgh Napier University

\section{Research}

Keywords: Coherence, Normalisation Process Theory, intervention description, speech and language therapy

Posted Date: May 29th, 2020

DOI: https://doi.org/10.21203/rs.3.rs-29982/v1

License: (9) This work is licensed under a Creative Commons Attribution 4.0 International License. Read Full License 


\section{Abstract}

Background Implementation depends on healthcare professionals making sense of a new intervention in relation to their routine practice, a process Normalisation Process Theory refers to as coherence. However, specifying what it takes to achieve coherence is challenging because of variation in new interventions, routine practice, and the relationship between them. Frameworks for intervention description offer a way forward in specifying coherence, as they provide broad descriptive categories for comparing complex interventions. To date such frameworks have not been informed by implementation theory, so do not account for the coherence work involved in holding aspects of routine practice constant while doing other aspects differently. Using speech and language therapy as an empirical exemplar, we explored therapists' experiences of practice change and developed a framework to show how coherence of child speech interventions is achieved.

Methods We conducted a retrospective case-based qualitative study of how interventions for child speech problems had changed across three NHS speech and language therapy services and private practice in Scotland. A coherence framework was derived through interplay between empirical work with 42 therapists (using in-depth interviews, or self-organised pairs or small focus groups) and Normalisation Process Theory's construct of coherence.

Findings Therapists reported a range of practice changes, which had demanded different types of coherence work. Non-traditional interventions had featured for many years in the profession's research literature but not in clinical practice. Achieving coherence with these interventions was intellectually demanding because they challenged the traditional linguistic assumptions underpinning routine practice. Implementation was also logistically demanding, and therapists felt they had little agency to vary what was locally conventional for their service. In addition, achieving coherence took considerable relational work. Non-traditional interventions were often difficult to explain to children and parents, involved culturally uncomfortable repetitive drills, and required therapists to do more tailoring of intervention for individual children.

Conclusions The intervention coherence framework has practical and theoretical applications. It is designed to help speech and language therapists anticipate and address barriers to coherence in their context when implementing non-routine interventions. It is also a worked example of using theory to make intervention description user-focused and implementation-friendly.

\section{Contributions to the literature}

- Intervention descriptions identify what healthcare professionals need to do to implement new interventions but not how this is the same or different from their routine practice. We applied qualitative research and implementation theory to this problem of specifying 'coherence'.

- We focused on speech and language therapists because their work and the interventions they use are very complex. By understanding changes in their routine practice, we identified key elements for achieving 
coherence.

- Our worked example of generating a coherence framework may be applicable in other professional areas where it is challenging to describe and implement complex behavioural interventions.

\section{Background}

How can we describe complex interventions in a way that supports their implementation?

The Consolidated Standards of Reporting Trials (CONSORT) group recommends the Template for Intervention Description and Replication (TIDieR) (1) as a minimum standard for reporting experimental and comparison interventions in trials and systematic reviews. It includes the name of the intervention; why the intervention was used; what materials and procedures were involved; who provided it and how, where, when, and how much; any tailoring or modification; and how well (planned and actually) it was delivered.

However, TIDieR may be limited in the support it can provide for implementation as it was designed from an innovator rather than an adopter perspective without taking account of implementation theory. Integrating a non-routine intervention into everyday practice is a social, context-sensitive and dynamic process (2). Basic technical detail is necessary but not sufficient to support the individual and collective work of implementation across a variety of local healthcare contexts where what is 'routine' differs (2).

Normalisation Process Theory (NPT) (3) was developed to help explain how healthcare professionals get the work of implementation done. This work includes comparing a new intervention to current practice before, during and after implementation to make sense of its implications through an individual and collective process of creating 'coherence' (3),(4) (Box 1).

\section{Box 1 Coherence (3),(4)}


'Coherence' is one of four core Normalisation Process Theory (NPT) constructs. NPT was developed to highlight that practices (including complex interventions) are ensembles of activity, and that implementing non-routine practices takes individual and collective work. NPT is intended to be used flexibly to help explain how people get this implementation work done.

NPT's core constructs cover the different work of implementation: coherence (work to make sense of the job that needs to be done), cognitive participation (the relational work of getting everyone who needs to be involved on board), collective action (working together to make it happen) and reflexive monitoring (working out the value of doing it).

The core construct of coherence (sense-making work) has four sub-constructs: differentiation, communal specification, individual specification, and internalisation:

- Differentiation is about how easily those involved can see that an intervention is different from current ways of working

- Communal specification is about how well, together, those involved can build a shared understanding of what an intervention is for

- Individual specification is about how well those who need to be involved grasp what specific tasks and responsibilities they have when using an intervention

- Internalisation is about how easily those involved notice what value an intervention might bring to their work

As a middle range theory applicable across implementation projects, NPT draws attention to the need for coherence work, but leaves healthcare professionals to figure out what this might entail. Implementation interacts with context and setting (5) and assumptions can be entrenched (6). Individually and collectively, implementers need to judge what they have the agency and potential to do differently at meso and micro levels.

Describing interventions in a way that supports coherence work is particularly challenging in fields such as child speech therapy where there are high levels of intervention complexity, ambiguity and ambivalence (additional file 1). A mixed method study of speech and language therapy for pre-school children in England involving 245 therapists confirmed that, from their perspective, intervention and its variation is difficult to describe without the caveat of 'it depends' (7). While this suggests therapists put considerable work into creating coherence in everyday practice, we know little about how coherence is achieved when a new intervention is introduced, or how this is affected by context. Therapists' coherence work may be largely invisible in the sociological sense of informal, behind-the-scenes labour that performs important social functions but may otherwise go unnoticed (8).

\section{Aim}

We sought to make coherence work more visible by identifying what therapists may have to hold constant or do differently to implement non-routine interventions as part of everyday child speech 
practice in their context. Our research question was: how do speech and language therapists describe the work of integrating complex interventions into their existing practice?

\section{Methods}

We referred to the Standards for Reporting Qualitative Research when drafting this paper (9).

\section{Research approach}

We conducted a retrospective qualitative study of practice change. Our overall purpose was to offer a 'best explanation' for practice change in a way that would support future implementation efforts. Our case-based sociological inquiry was underpinned by the meta-theoretical approach of critical realism (10),(11). It progressed through an interplay between empirical work, based on therapists' accounts of how they had already changed their practice, and theoretical ideas about implementation.

\section{Reflexivity}

The main author (AN) is a speech and language therapist researcher interested in the work of practice change as a social process. To maintain an implementation-in-practice perspective she drew on her historical experience as a therapist and editor of a practice magazine and avoided immersion in the child speech intervention research literature. Throughout, she used feedback from co-authors (experienced health service researchers from a sociology background) to reflect critically on how her assumptions may be shaping or constraining the research. This drew her attention to the gap between the research-based idea of a complex intervention as a 'thing' to implement and the actual experience of creating coherence in clinical practice.

\section{Sampling strategy}

Sampling was an iterative process of configuring cases ('casing') (12),(13). It involved constantly asking 'what is this a case of?' and purposefully seeking data that could reasonably be expected to help test and refine that theory. Data context was part of the decision-making process. People with actual connections to each other in relation to the research question were sampled to highlight how things 'got done' collectively (or did not) and to provide opportunities to corroborate and refine emerging theories (14). Additional file 2 is a summary of sampling questions and decisions.

The 42 participants came from three NHS speech and language therapy services (anonymised as Blaeshire, Clootshire and Staneshire) and private practice in Scotland. They were sampled 'in context' so that actual connections and service structure could also be taken into account. In brief, Blaeshire had invested in a sustained initiative to introduce new child speech interventions, while a part of Clootshire was exploring ways to deliver greater intensity of intervention for children who needed it. Staneshire and another part of Clootshire were shifting resources away from direct intervention, although therapists could still try out new interventions if they wished. Sampling began chronologically and became more purposive, ending when we judged information power to be adequate (15). 


\section{Technical processes of ethics, data collection and data management}

The study was approved by Stirling University's School of Health Sciences Ethics Committee on 19th November 2014. R\&D Management Approval was received from all three participating NHS services by 31st March 2015, and Letters of Access issued.

AN approached speech and language therapy managers of the three services. They agreed to an initial discussion followed by staff meetings to talk about the study and seek permission to contact by email without obligation. All processes were designed to maintain confidentiality, e.g. AN did not discuss with managers or participants who had declined, consented or taken part, and offered participants any place, time, or mode of contact.

An estimated $88 \mathrm{NHS}$ therapists were eligible, of whom 81 gave permission to contact. Eight did not respond, 15 declined, and six did not return consent forms, leaving 52 potential NHS participants. An estimated 21 private practitioners could have volunteered of whom four completed the consent process. At interview, 9/42 participants were based in Clootshire, 11/42 in Staneshire, 19/42 in Blaeshire, and 3/42 were private practitioners. Most elected to have an individual interview $(n=28)$, including one by telephone, while four chose to have paired interviews $(n=2)$ and 10 to participate as small-team focus groups $(n=3)$.

AN conducted all interviews and focus groups. All encounters were audio recorded, with time averaging 78 minutes (range 48 to 112 minutes). Some participants provided artefacts, including two protocols developed for parent groups.

Electronic data was held on a secure, password-protected university computer, and paper data stored securely. File labelling did not compromise confidentiality. Digital voice recordings were transferred to the computer as soon as possible, and the recording deleted from the portable device. Electronic data was managed within NVivo 10, Excel and Word.

\section{Data collection and interplay with theory}

AN conducted all contact, interviews and focus groups in a conversational manner. She invited participants to suggest the practice change(s) they wished to discuss, and made constant judgements around pausing, probing, reassuring, empathising, and encouraging feedback and comparisons.

Interplay with theory was integral to how data collection unfolded. At an early stage of interviewing, AN recognised that NPT's core construct of coherence was central to unpacking the nature of child speech intervention and what it takes to change routine practice. Interviews and focus groups were themselves sites of coherence, as participants sought to articulate practice changes and AN encouraged them to consider how a change differed from what they had done before, or how their experience compared to those of others. 


\section{Data analysis}

In transcribing all encounters, AN paid attention to accuracy and turn-taking, noting emphasis, hesitation and humour to aid analysis. She used the process of anonymising data to deepen her awareness of how context may have shaped and constrained therapists' actions. This included: giving pseudonyms to participants, services and any non-participants named in interviews; coding the structure of each service; and banding demographic data such as year of qualification and whole-time equivalence.

We used a realist approach to qualitative analysis to make sense of the diversity of practice change (16). Our analysis focused on describing child speech intervention according to therapists' reports of how their intervention had - and had not - changed over time.

AN identified, organised and categorised the numerous practice changes raised by therapists in an iterative process. This led to analytical separation of 'intervention' from three other aspects of practice change: the service; caseloads; and candidacy. Candidacy (17) refers to who is considered eligible for starting, continuing with and ending therapy. These aspects will be reported elsewhere.

We compared data and ideas using connecting and categorising activities (16). These included indexes, maps, tables, summaries, ethnographic monologues and a contribution matrix. Two transcripts were intensity sampled for detailed coding because these interviews were nuanced explorations of practice change in relation to complex interventions; the importance of the NPT differentiation component was identified in the process of coding the first, with "the same yet very different" a preliminary mechanism. Two documents (group plans) were also compared. Counterfactual thinking (18) took account of absence as well as presence, for example asking "What is it about particular interventions that makes them possible (or not) to consider and use?"

AN explored the tension between intervention(s) as parts and a whole (19) through writing around interviewees' experiences of adaptation. These included the concept of fidelity, reasons to adapt, using parts, combining parts of interventions, shifting the weight of routine intervention, and deimplementation. She arrived at the coherence framework through progressive casing (12).

\section{Techniques to enhance trustworthiness}

AN maintained a critical stance through underpinning questions including "What other explanation might there be?" and "Where might I be wrong?" She recorded developing ideas through memos and sketches, testing them with successive interviewees and with two recently retired senior therapists. The co-authors read purposively selected transcripts and regularly offered critical feedback and a different perspective.

Judgement of the adequacy of the sample to help answer the research question informed the decision to stop gathering empirical data (15) (Table 1). 
Table 1

Judging adequacy of sample by information power (15)

\begin{tabular}{|llllll|}
\hline Criterion & $\begin{array}{l}\text { Study } \\
\text { aim }\end{array}$ & $\begin{array}{l}\text { Sample } \\
\text { specificity }\end{array}$ & $\begin{array}{l}\text { Use of } \\
\text { theory }\end{array}$ & $\begin{array}{l}\text { Quality of } \\
\text { dialogue }\end{array}$ & $\begin{array}{l}\text { Analysis } \\
\text { strategy }\end{array}$ \\
\hline $\begin{array}{l}\text { Lower } \\
\text { sample }\end{array}$ & Narrow & Dense & Applied & Strong & Case \\
\hline $\begin{array}{l}\text { Higher } \\
\text { sample }\end{array}$ & Broad & Sparse & Not applied & Weak & Cross-case \\
\hline
\end{tabular}

\section{Findings}

Participants referred to a pattern of practice which served as a shared context for how child speech practice as a whole had changed. Sally suggested this pattern was typical around 30 years ago, while Hazel observed laughingly it was "what I would have maybe done in 1981?" Although at that time therapists worked in isolation and had considerable autonomy, intervention had a similar pattern. It focused on one speech sound at a time with a child once a week through a peripatetic service in clinics and schools, with neither parents nor teachers routinely involved.

Change had been driven by a range of factors to which participants had been exposed in a variety of ways. These included: developments in policy, the profession and the evidence base; what had happened locally to services over time; practical experience with a range of clients; and education and learning opportunities. Interventions for child speech had become more varied but remained challenging to describe. Aileen was aware of two research initiatives aimed at separating out and specifying interventions but reflected, "the more (laughing) I think about it, the more I realise it's a total mixed bag that I'm using all the time". Sonia illustrated the fit of the coherence construct when she described eclecticism as not "a bit of that and a bit of this" but a thoughtful combination that "amalgamates into the whole really".

\section{Coherence work in child speech intervention}

Here, we illustrate how context impacted on coherence work when a new intervention was introduced to existing routine practice. Examples of how the four NPT coherence constructs help explain what was happening are highlighted as [Differentiation], [Communal specification], [Individual specification] and [Internalisation].

\section{Coherence work: non-traditional theory}

Participants consistently referred to 'traditional' intervention. There was consensus over what it was, and it appeared entrenched. Theories underpinning traditional intervention included attending to how speech sounds are produced (articulation), contrasted (phonology) and manipulated (phonological awareness), as well as to where the speech chain is breaking down (psycholinguistic models). 
Non-traditional interventions were a heterogeneous group recognised as 'new' to clinical practice within the last six years but not to the literature. They challenged traditional linguistic assumptions [Differentiation], meaning therapists had to work harder to make sense of and feel comfortable with them. Some reported benefits such as more targeted therapy and faster progress [Internalisation].

Therapists who had tried non-traditional interventions expressed surprise and often embarrassment that they had not known about them. On moving to a new service, Erin remembered, "It was really eye-opening coming here actually. Cos I just had no...I had no clue and I just thought I can't believe, you know, that I didn't know about this." Wendy returned from maternity leave and noticed "a huge, kind of vast change in where everybody's thinking was now."

Even where therapists were aware of non-traditional approaches, there was a consistent mismatch with what they saw in practice [Communal specification]. This was most evident from more recently qualified participants.

Megan: I remember at university, actually, they talked about doing the complex sounds first? And then that the others would fall into place. It's one thing l've never tried.

Interviewer: And presumably never seen anybody else-

Megan: No... and never really heard anyone else speak about doing it. I just remember it being a suggestion in one of the textbooks.

Traditional elements made theoretical sense to therapists, while non-traditional elements were unsettling [Individual specification]. Isla was initially nervous when using an evidence-based intervention where targets are chosen by the child. A 4-year old wanted to say words like 'waterslide', 'karate' and 'Cinderella', "things that you would think from a therapist's point of view ((puts on fed-up voice)) 'oh! That's going to be really hard! She's not going to manage that"'. Diane repeatedly used the word "strange" to describe a demonstration video of an evidence-based intervention where the therapist did not help the child correct their speech:

Jackie: I find that really hard sitting there

Diane: I thought that was strange

Jackie: Listening to a child.. not achieving for.. for.. (overlapping) a long time

Diane: And you're saying 'oh good try' [[yeah]].. but you're not really..

Nicole: And if THEY know (laughs), if they know that they're not achieving, that's really hard

The entrenchment of traditional intervention in the profession was also confirmed by what happened when it was questioned [Internalisation]. Carolyn asked for training in non-traditional approaches, and "it was sort of a bit, as I was told, 'well that's your bread and butter', it's sort of an assumption that kind of 
somehow you know everything there is to know". When Emily was on student placements, "you're like, 'so which approach are you using?', they go 'oh well I use a combination' (pause) em, so that was sort of my learning of oh you don't have to use just one or the other religiously". Elizabeth interjected phrases such as "I feel like I'm a heathen now" and "it's a bit illegal to say that" when she wondered whether the tasks that children are traditionally expected to do before they can move on to other ones actually do predict improvement.

The coherence of traditional theories of intervention - and the struggle to find coherence with nontraditional theories - suggests that, as a profession, systematic support is needed for the theoretical work of implementing non-traditional interventions. As discussed in the next section, coherence of logistical work was more dependent on local convention.

\section{Coherence work: unconventional logistics}

Logistical elements of intervention were where the client was seen (clinic; nursery or school; home), the format (e.g. a group or one-to-one; whether and how parents were involved) and dosage (e.g. number of sessions in a week over what duration). Services introduced unconventional logistics to meet priorities such as reducing waiting lists or shifting resources from specialist to universal provision. However, therapists had little agency to vary where, how and when they saw clients, with implications for coherence of non-traditional interventions.

Therapists often had to experience a change from a conventional to a non-conventional place before they realised the impact it had on other intervention elements [Internalisation]. For example, Kate missed the "more calming environment" of a clinic because the busyness, noise and lack of opportunity to involve parents at education premises constrained what intervention was possible. Moving from NHS to private practice gave rise to unexpected benefits when therapists worked in clients' homes. Isobel noticed "I think about the child in the whole, way more than I did before". She also found it easier to involve parents because "when they are in the situation, you make them think about 'how can you implement?"'

Where schools had been the conventional place, without parents present, the consequences of a shift to clinics were surprising. Maureen found it helped make the tasks and responsibilities of non-traditional interventions apparent [Individual specification]:

With a parent sitting in front of you as well, when you're asking them to commit to therapy with their child, it almost felt like you wanted to have more of a rationale for what you were doing...

This opportunity to build a shared understanding [Communal specification] meant she felt more confident negotiating intensive dosage ("'the evidence for this is this amount of intervention will bring about successes"'). Dosage was, however, the logistical convention therapists felt least able to address as shown by observations such as "that is how (pause) we're sort of programmed to be". Vivienne had experimented with an evidence-based non-traditional intervention, but its required dosage was unconventional for her service [Differentiation]: 
...it's meant to have at least 60 minutes a week, and I'm not seeing anybody more than once a week. Most of them are lucky to be seen once a week.

Instead, therapists varied intervention dosage through shortening recommended length, number or frequency of sessions to the local convention, and asking parents to do more.

Although participants used parent groups for other client groups, they were unconventional for child speech [Differentiation]. Jenna and colleagues now started with two parent group sessions, so parents would see themselves as capable of doing speech work [Communal specification]:

...demonstrating all the time how you would carry out these activities with your child. And we have another booklet - we've got booklets for everything - that they can go back through and read up on. 'This is the steps, this is how you do it.' So we're trying to be as supportive as possible.

The other child speech parent group also had two sessions but had been introduced to increase throughput, was poorly attended, and therapists saw it as ineffective. Melanie reflected on what was invested in this "massive" service change [Internalisation]:

we wanted to try it on a small scale, and maybe try and test that to see if it was effective...but I think there was just high demands from 'we just need to do this' and get it rolled out across. So it's always trying to balance that out and, you know, are we being effective against 'oh we just need to see these people and get them off the waiting list'

Non-traditional interventions were not used either in a parent group, or when intervention was delegated to parents or education staff. The next section helps explain why they may have been unsuitable for these formats.

\section{Coherence work: relating non-traditional interventions to clients}

Speech and language therapists manage cases (children and their parents) and caseloads. Nontraditional interventions challenged the coherence of this relational work.

Therapy for child speech necessarily involves meta-language (talking about talking). It became clear that this applied both to talking about the child's speech problem and talking about a particular intervention in ways that made sense to people who don't have specialist linguistic knowledge [Communal specification]. Louise drew attention to this problem with non-traditional interventions:

How are you gonna pass that on to parents? (laughs) How are you gonna explain? 'Cos I think some of these concepts... these approaches are very complicated. (pause) REALLY complicated... So it's ultimately down to the, you know, it's down to your skills in terms of how you're able to present that...

Although many participants had spent time learning about non-traditional interventions, the metalinguistic demands were not addressed in intervention descriptions. How non-traditional interventions impacted on routine session plans also appeared relatively invisible from the literature. Implementing 
such interventions made Erin "realise how set in your ways you get" and how traditional intervention had "this same same same same session plan that you go along with". She wondered how it was possible that she was still doing similar activities for non-traditional intervention yet "every session for every child is totally different?" [Differentiation].

The need to individualise non-traditional interventions also extended to therapy materials [Individual specification]. Traditional intervention lent itself to pre-prepared generic sets of materials sorted into folders and boxes for easy transport and adaptable use. As Fran said, "I could just grab that" whereas preparing materials for non-traditional approaches was "very very time-consuming" and "there's no way that you just would grab - d'you know?" However, it helped that a favourite source of child speech materials (Black Sheep Press) has resources which can support implementation of non-traditional intervention targets. On placing a recent order, Jess was amused when confronted with the previous pattern: "you can totally see how your thinking's changed!"

The clearest relational challenge to coherence of non-traditional interventions came from the impact on support and feedback strategies therapists used to guide the child through therapy. Therapists talked about routinely shifting the power of the relationship to give the child control and being facilitative and non-directive. However, non-traditional interventions often called for directive techniques such as repetitive practice (drilling). Because it was important to make therapy fun and interesting - possibly for themselves as well as clients - therapists were conflicted by the idea of drilling [Internalisation]. Beverly acknowledged, "it is drills, it is repetitive, it's not the most exciting therapy work". Not only was it unexciting in itself, but implementing it reduced the kind of rewards that could be used; as Heather observed, "it's hard because the more exciting you make it the longer it becomes!" Elizabeth had made a conscious decision to use drilling as part of implementing non-traditional interventions but noted it "seems more acceptable to drill in American texts than it is here", adding:

I don't know, it's funny isn't it? It's maybe a feeling that you're doing something to the child and...it's like making the child into some passive recipient...

Where there is a strong rationale for drilling, this cultural barrier may need to be explicitly addressed.

\section{Framing coherence in child speech intervention}

To make the coherence work described by therapists more visible, we configured an explanatory framework. It is based on what participating therapists had changed or held constant, taking account of how this was shaped and constrained by context. The framework has three inter-related parts (Table 2):

1. Ten changeable elements of child speech intervention

2. Binary contextual characteristics that made coherence work more or less challenging

3. The main types of work therapists had to do to deliver or change these elements: theoretical (intellectual), logistical (organisational) and relational (people) work 
In summary, theoretical coherence work was increased if elements of intervention were non-traditional for the speech and language therapy profession. Logistical coherence work was increased if elements of intervention were unconventional for the local service. Relational coherence work was increased if therapists had to do more tailoring of intervention elements. Overall, the framework shows that a new intervention demands the most coherence work when it needs a non-traditional approach, target and focus, an unconventional place, format and dosage, and comes with an unspecified meta-language, an incongruent scaffold, a non-routine session plan and the need for individualised materials.

Table 2

Child speech intervention coherence framework

\begin{tabular}{|c|c|c|c|}
\hline Work & Element & Brief definition of element & $\begin{array}{l}\text { How context } \\
\text { impacts on } \\
\text { coherence }\end{array}$ \\
\hline \multirow[t]{3}{*}{ Theoretical } & Approach & $\begin{array}{l}\text { Theory of an intervention's power to effect change } \\
\text { in speech }\end{array}$ & $\begin{array}{l}\text { Traditional / Non- } \\
\text { traditional }\end{array}$ \\
\hline & Target & Sounds child is asked to work with & $\begin{array}{l}\text { Traditional / Non- } \\
\text { traditional }\end{array}$ \\
\hline & Focus & $\begin{array}{l}\text { Tasks child is asked to do (e.g. listen, compare, } \\
\text { produce words) }\end{array}$ & $\begin{array}{l}\text { Traditional / Non- } \\
\text { traditional }\end{array}$ \\
\hline \multirow[t]{3}{*}{ Logistical } & Place & Where a child is seen for intervention & $\begin{array}{l}\text { Locally } \\
\text { conventional / } \\
\text { Locally } \\
\text { unconventional }\end{array}$ \\
\hline & Format & $\begin{array}{l}\text { How people are involved (e.g. alone or group; } \\
\text { parents; assistant) }\end{array}$ & $\begin{array}{l}\text { Conventional / } \\
\text { Unconventional }\end{array}$ \\
\hline & Dosage & $\begin{array}{l}\text { The idea that quantity of intervention can make a } \\
\text { difference (e.g. how much, how often, how } \\
\text { repetitively, for how long) }\end{array}$ & $\begin{array}{l}\text { Conventional / } \\
\text { Unconventional }\end{array}$ \\
\hline \multirow[t]{4}{*}{ Relational } & $\begin{array}{l}\text { Meta- } \\
\text { language }\end{array}$ & $\begin{array}{l}\text { Shared way of talking about speech sounds and } \\
\text { intervention }\end{array}$ & $\begin{array}{l}\text { Specified / } \\
\text { Unspecified }\end{array}$ \\
\hline & Scaffold & $\begin{array}{l}\text { How behavioural techniques are used to support } \\
\text { progress }\end{array}$ & $\begin{array}{l}\text { Congruent / } \\
\text { Incongruent }\end{array}$ \\
\hline & Session & How intervention is structured within each visit & $\begin{array}{l}\text { Routine / Non- } \\
\text { routine }\end{array}$ \\
\hline & Material & How things are used to make intervention fun & $\begin{array}{l}\text { Adaptable / } \\
\text { Individual }\end{array}$ \\
\hline
\end{tabular}

\section{Discussion}

Our intervention coherence framework describes what therapists may have to do differently to implement a non-routine intervention as part of everyday child speech practice in their context. It was generated through a retrospective qualitative study of practice change with child speech therapy as an intensive 
case (20). Because it was informed by implementation theory, the concept, approach and aspects of the findings may have transferability to other healthcare professionals who use complex behavioural interventions.

Although we studied implementation, our theoretical lens was more social science than implementation science (21). Social science has provided considerable insights into the complexities of describing clinical practice and accounting for the influence of context. Gabbay and le May's ethnography with clinicians in primary care (22) identified the 'mindlines' that make practice happen and provide a vehicle for changing it. Recognising that procedural aspects of surgery are easier to describe than the human experience, Cristancho et al (23) used 'rich pictures' to reveal the social, cultural and personal influences at play.

Reconciling interventions as 'things' which can be described with how implementation is experienced in routine practice is, however, an ongoing methodological challenge. Intervention components have more or less plasticity to be moulded, contexts more or less elasticity to accommodate new interventions, and healthcare professionals have to maintain a service while implementing non-routine interventions (24). Instead of beginning with a description of evidence-based complex interventions and examining how they were implemented (or not), we therefore began by exploring what practice changes had already been possible (or not), and how this varied by context (or did not).

In shifting the empirical focus of description efforts from the innovator (developer) to the intended adopter (user), we are also responding to Horton et al's (2) argument for research approaches that might increase the likelihood of intervention spread. Innovator-focused intervention description gives priority to technical detail about 'how it ought to be done', while adopter-focused description is about 'what it might take to get it done'.

Coherence is one of four dynamically interacting NPT mechanisms underpinning implementation, along with cognitive participation, collective action, and reflexive monitoring. A systematic review of how NPT has been used in feasibility studies and process evaluations of complex healthcare interventions $(n=$ 108) identified that, of the four, coherence was mainly seen as "an obligatory point of departure for implementation processes...sometimes at the expense of other activities" (25) p. 15. Our concentration on coherence does not imply that it preceded or was more important than the other mechanisms. Although we selected it purposively for its relevance to intervention description, much sense-making was only possible for participants through the doing.

An NPT-informed retrospective qualitative study of implementation of a shared decision making programme identified that coherence was often missing (26). As implementation is more complex than delivering an intervention to patients, they concluded "How to achieve 'coherence' in practice is the next logical research question" (26) p. 7. The intervention coherence framework is a step in that direction.

As with all frameworks, the number and scope of elements is a fallible and somewhat arbitrary effort to balance level of nuance with purpose, i.e. differences that matter in practice. The intervention coherence 
framework has 10 elements, with contextual considerations presented as binaries. By indicating the main type of work required, it makes explicit that implementation depends on addressing routines and assumptions of the profession and services, not just therapists. It could be used by services to map the extent and type of work and support a particular intervention would demand. Based on our participants' experience, this could include specifying elements of coherence where barriers might not have been anticipated (e.g. meta-language, session planning, or incongruent therapeutic behaviours).

Our adopter-focused coherence framework is complementary to innovator-focused intervention description and it is instructive to consider whether these different perspectives make a difference to the content. The intervention coherence framework explicates the 'what' and 'tailoring' elements of intervention in the generic TIDieR framework (1) but omits 'how well'. With 72 elements, the child speech specific Phonological Intervention Taxonomy (27) is more detailed and, like TIDieR, is focused on following procedures with fidelity. However, its 15 subcategories highlight the importance of linguistic knowledge, logistical considerations, people skills and materials, all of which are covered in the intervention coherence framework. Our meta-language element also supports Morgan et al's finding that parent understanding of intervention is important to therapists but under-investigated (7).

The novel and transferable contribution of the intervention coherence framework is less in its identified elements of intervention than the way it relates these to the dynamic work and context of implementation. This may be particularly helpful where there is intervention complexity, ambiguity and ambivalence. A recent scoping study, for example, used qualitative methods to make sense of the approaches, practices, service models and ways of working that characterise physiotherapy, occupational therapy and speech and language therapy for children with neuro-disability (28). Conclusions emphasised the state of dynamic change and development the professions are operating in, the heterogeneity of the client group, the many potential 'active ingredients' and uncertainty over mechanisms of change. To support coherence work, a descriptive framework that identifies what could be held constant is therefore as important as identifying what needs to change.

\section{Limitations}

A key strength of this study (sampling) is also a limitation, as we purposively sought the perspective of therapists and have therefore not accounted for the coherence work this creates for other people such as assistants, educators, parents or children. To ensure actual connections, sampling was limited to Scotland, so it is unclear to what extent these particular practice changes apply to practice change elsewhere. In addition, to achieve a practice perspective, it was important to move outside the frame of evidence-based practice, so our decisions to include practice changes were not dependent on their proven effectiveness. This is however mitigated by the inclusion of Blaeshire, where there had been a planned programme to implement non-traditional evidence-based interventions.

\section{Conclusion And Recommendations}


So, how can we describe complex interventions in a way that supports their implementation?

Our findings confirm that coherence work is both integral to clinical practice and central to changing it. They take into account that healthcare professionals, professions and services have different starting points for practice change. They also extend practical application of NPT's coherence construct to the field of intervention description.

The intervention coherence framework comprises what our research suggests should be discussed if individual and collective coherence is to be achieved when implementing non-routine child speech interventions. A number of participants referred to making or finding simple plotting devices helpful for decision making. We have therefore laid the framework out for testing as a heuristic tool (additional file 3) to aid decision making and planning around implementation.

\section{Abbreviations}

CONSORT: Consolidated Standards of Reporting Trials; NPT: Normalisation Process Theory; TIDieR: Template for Intervention Description and Replication

\section{Declarations}

\section{Ethics approval and consent to participate}

The study was approved by Stirling University's School of Health Sciences Ethics Committee on 19th November 2014. Redistribution of sampling across sites and an email about the study for the Association of Speech and Language Therapists were approved by Chair's Action. R\&D Management Approval was received from all three participating NHS services by 31st March 2015, and Letters of Access issued. Written, signed and dated informed consent was received from all participants prior to participation.

\section{Consent for publication}

The signed participant consent form included item 5: 'I understand that anonymous direct quotations from my interview / focus group may be used in study publications and presentations.'

\section{Availability of data and materials}

The signed participant consent form included item 6: 'I understand that at the end of the study anonymised transcripts will be donated to a secure archive for future use by researchers.' This will be done when publications are complete. This paper builds on a thesis where further data is available: 
Nicoll A. Speech and language therapy in practice: a critical realist account of how and why speech and language therapists in community settings in Scotland have changed their intervention for children with speech sound disorders. http://hdl.handle.net/1893/27257: University of Stirling; 2017.

\section{Competing interests}

The authors declare that they have no competing interests.

\section{Funding}

This paper is based on work carried out as part of an ESRC funded PhD studentship awarded to AN at the NMAHP Research Unit, University of Stirling. The funder had no role in study design, data collection and analysis, decision to publish, or preparation of the manuscript.

\section{Authors' contributions}

AN conceived and conducted the study with guidance, critical feedback and oversight from BW and MM. AN wrote the manuscript. MM and BW commented critically on drafts of the paper. All authors read and approved the final manuscript.

\section{Acknowledgements}

Thank you to all participants for giving so generously of their time and expertise, and to the services and people who facilitated access. Thanks also to retired speech and language therapists Linda Armstrong and Jen Reid for critical feedback throughout the research, and to Marian Brady at NMAHP Research Unit, Glasgow Caledonian University for the many discussions around TIDieR as well as critical feedback on early versions of this paper.

\section{References}

1. Hoffmann TC, Glasziou PP, Boutron I, Milne R, Perera R, Moher D, et al. Better reporting of interventions: template for intervention description and replication (TIDieR) checklist and guide. BMJ : British Medical Journal. 2014;348:g1687.

2. Horton TJ, Illingworth JH, Warburton WHP. Overcoming challenges In codifying and replicating complex health care interventions. Health Affairs. 2018;37(2):191-7.

3. May C, Finch T. Implementing, embedding, and integrating practices: an outline of Normalization Process Theory. Sociology. 2009;43(3):535-54. 
4. Rapley T, Girling M, Mair FS, Murray E, Treweek S, McColl E, et al. Improving the normalization of complex interventions: part 1 - development of the NoMAD instrument for assessing implementation work based on normalization process theory (NPT). BMC Medical Research Methodology. 2018;18(1):133.

5. Pfadenhauer LM, Gerhardus A, Mozygemba K, Lysdahl KB, Booth A, Hofmann B, et al. Making sense of complexity in context and implementation: the Context and Implementation of Complex Interventions (CICl) framework. Implementation Science. 2017;12(1):21.

6. Montini T, Graham ID. "Entrenched practices and other biases": unpacking the historical, economic, professional, and social resistance to de-implementation. Implementation Science. 2015;10(1):24.

7. Morgan L, Marshall J, Harding S, Powell G, Wren Y, Coad J, et al. 'It depends': characterizing speech and language therapy for preschool children with developmental speech and language disorders. International Journal of Language \& Communication Disorders. 2019;54(6):954-70.

8. Hatton E. Mechanisms of invisibility: rethinking the concept of invisible work. Work, Employment and Society. 2017;31(2):336-51.

9. O'Brien BC, Harris IB, Beckman TJ, Reed DA, Cook DA. Standards for Reporting Qualitative Research: a synthesis of recommendations. Academic Medicine. 2014;89(9):1245-51.

10. Archer M, Decoteau C, Gorski P, Little D, Porpora D, Rutzou T, et al. What is critical realism? Perspectives. 2016(December).

11. Porpora DV. Reconstructing sociology: the critical realist approach. Cambridge: Cambridge University Press; 2015.

12. Emmel N. Sampling and choosing cases in qualitative research: a realist approach. London: SAGE; 2013.

13. Ragin CC. "Casing" and the process of social inquiry. In: Ragin CCB, Howard S, editor. What is a case? Exploring the foundations of social inquiry. Cambridge: Cambridge University Press; 1992. p. 217-26.

14. Sayer A. Method in social science. Hoboken: Taylor \& Francis; 2010.

15. Malterud K, Siersma VD, Guassora AD. Sample size in qualitative interview studies: guided by information power. Qualitative Health Research. 2016;26(13):1753-60.

16. Maxwell JA. A realist approach for qualitative research. London: SAGE; 2012.

17. Dixon-Woods M, Cavers D, Agarwal S, Annandale E, Arthur A, Harvey J, et al. Conducting a critical interpretive synthesis of the literature on access to healthcare by vulnerable groups. BMC Medical Research Methodology. 2006;6(1):35.

18. Danermark B, Ekstrom M, Jakobsen L, Karlsson JC. Explaining society: critical realism in the social sciences. Abingdon: Routledge; 2002.

19. Clark AM. What are the components of complex interventions in healthcare? Theorizing approaches to parts, powers and the whole intervention. Social Science \& Medicine. 2013;93:185-93.

20. Patton MQ. Purposeful sampling. Qualitative evaluation and research methods. Beverly Hills, CA: SAGE; 1990. p. 169-86. 
21. Greenhalgh T, Papoutsi C. Studying complexity in health services research: desperately seeking an overdue paradigm shift. BMC Medicine. 2018;16(1):95.

22. Gabbay J, le May A. Practice-based evidence for healthcare. London: Routledge; 2011.

23. Cristancho S, Bidinosti S, Lingard L, Novick R, Ott M, Forbes T. Seeing in different ways:introducing "rich pictures"in the study of expert judgment. Qualitative Health Research. 2015;25(5):713-25.

24. May CR, Johnson M, Finch T. Implementation, context and complexity. Implementation Science. 2016;11(1):141.

25. May CR, Cummings A, Girling M, Bracher M, Mair FS, May CM, et al. Using Normalization Process Theory in feasibility studies and process evaluations of complex healthcare interventions: a systematic review. Implementation Science. 2018;13(1):80.

26. Lloyd A, Joseph-Williams N, Edwards A, Rix A, Elwyn G. Patchy 'coherence': using normalization process theory to evaluate a multi-faceted shared decision making implementation program (MAGIC). Implementation Science. 2013;8(1):102.

27. Baker E, Williams AL, McLeod S, McCauley R. Elements of phonological interventions for children with speech sound disorders: the development of a taxonomy. American Journal of SpeechLanguage Pathology. 2018;27(3):906-35.

28. Beresford B, Clarke S, Maddison J. Therapy interventions for children with neurodisabilities: a qualitative scoping study. Health Technology Assessment. 2018;22(3).

\section{Supplementary Files}

This is a list of supplementary files associated with this preprint. Click to download.

- Additionalfile1Childspeechasaninformationrichfield.docx

- 04262SRQRChecklistANMMBW210520.docx

- Additionalfile2Samplingquestionsanddecisions.docx

- Additionalfile3Mappingchallengestocoherence.docx 